this trend.

- The changes in research funding are not only indicative of other changes in the fiscal reality for higher education, but of other changes as well. Basic research is less emphasized as government funding diminishes and as the quest for "results" and immediate payoff takes precedent. For a half-century or more, universities were seen as the home of basic research-scientific research that would yield results in the long term but might have little immediate benefit. Funders are now less willing to support this kind of research. Accountability for research results is an increasing part of the pattern.

- The academic profession will increasingly lose power in the context of accountability and budgetary difficulties. In a difficult job market with limited mobility at the upper levels of the profession, academics are simply at a disadvantage. Those who have control over the budget will gain the upper hand-senior administrators will inevitably wield more authority, and the faculty will have less control over the university. One of the implications of this trend will be a lessening of autonomy.

- The differentiation between the "haves" and the "have nots" among institutions and in the academic profession, will continue, and perhaps even become exacerbated. The "research cadre"-those senior professors located mainly at the top 50 to 75 American universities, with a strong commitment to research, access to external funding, and low teaching loads-will find that their working conditions may deteriorate modestly, but that they will be able to continue functioning with minimal deterioration. The significant declines will occur at the second tier institutions. It is likely that the system will be further segmented by the expansion in the number of "non-tenure-track" full-time contract faculty hired mainly to teach, and of the continued growth of part-time faculty, creating a "three-class" professoriate.

- The sense of community, on the decline since the 1950s, will further deteriorate as the professoriate is divided demographically and by competing interests, increasingly differentiated institutions, and other forces.

These factors do not constitute a revolution in the academic profession, and we foresee academic life in the American university continuing on largely as before. Yet, the pressures on the academic profession will be unprecedented and significant change will inevitably take place. The new realities will affect different segments of the profession in different ways-but there is no doubt that we are in a period of challenge.

\section{The World Bank and UNESCO on Higher Education}

\section{Rollin Kent}

Rollin Kent is a professor in the Departamento de Investigaciones Educativas, Centro de Investigación y Estudios Avanzados, San Borja, México. Address: Departamento de Investigaciones Educativas, Centro de Investigación y Estudios Avanzados, San Borja 938, México, D.F. 03100. Tel: (525) 559-4232; fax: (525) 575-0320; e-mail: RKENT@UDLAPVMS.PUE.UDLAP.MX

$I^{n}$ $\mathrm{n}$ the mid-1990s, the policy debate on higher education has moved to the international arena. Multilateral lending organizations have spurred the debate, as illustrated by the World Bank's 1994 publication, Higher Education: The Lesson of Experience. In addition, UNESCO has been active in promoting international debate through its recent publication, Policy Paper for Change and Development in Higher Education. How do these positions compare in terms of their diagnosis of current problems in higher education and their prescriptions?

\section{The Diagnosis}

The starting point for both positions is that higher education today is in crisis. Both papers agree that the current situation is not sustainable in the medium and long term. According to the World Bank, higher education is in crisis throughout the world in terms of: low quality, because of rapid enrollment growth under conditions of limited resources; inefficiency, in terms of inappropriate use of public resources in higher education, high dropout rates, and program duplication; and inequity, because "public subsidies as a proportion of unit costs of higher education often far exceed the subsidies to primary and secondary education." The question of management and institutional leadership stands out as well. There can be no doubt that without serious attention to the institutional level - that is, management, leadership, the use and accountability of public resources, etc.-little progress can be expected in higher education reform.

UNESCO points out three important trends throughout the world: enormous quantitative expansion, which has nonetheless not led to increased equality of access and has not resulted in a proportionally large production of engineers and scientists; ${ }^{1}$ inadequate diversification of institutions, and academic programs that do not comply with minimum standards and have not led to significant educational innovations; and expansion in an increasingly constrained financial environment, where spending per student has not kept pace with the growing numbers of students 
enrolled. A paradox becomes evident: developing countries, especially the poorer ones, spend an increasing proportion of their GNP on each student in public higher education than do developed nations. UNESCO states that no country can sustain a viable and differentiated system of higher education on purely public funds.

\section{The Prescriptions}

The basic prescriptions made by the World Bank for higher education are:

- encouraging institutional differentiation, especially development of the private sector;

- diversifying funding sources, including cost-sharing with students and linking government funding closely to performance;

- redefining the role of government in its relationships with higher education;

- focusing on quality, responsiveness, and equity;

- redefining the role of government to ensure a coherent policy framework, create oversight bodies to monitor institutional performance, evaluate funding requests and make relevant information available to the various stakeholders in higher education;

- greater reliance on incentives and market-oriented instruments to implement policies; and

- increasing management autonomy for public institutions and decentralizing all key management functions (e.g., setting fees, recruiting and retrenching personnel, and using budgetary allocations flexibly across expenditure categories), while holding institutions accountable using sophisticated evaluation criteria.

As for UNESCO 's prescriptions, rather than specific recipes for reform, they propose a general platform. The challenge of sustainable development implies that institutions of higher education take a hard look at themselves in terms of their relationships to the economy, their organizational structures, and their funding and spending mechanisms.

As for UNESCO 's prescriptions, rather than specific recipes for reform, they propose a general platform. The challenge of sustainable development implies that institutions of higher education take a hard look at themselves in terms of their relationships to the economy, their organizational structures, and their funding and spending mechanisms.
The principal imperative that nations face today is raising their capacity to adapt to rapid changes in their economic, technological, political, and cultural environments. Developing countries, in particular, face the dual challenges of developing their human resources and reducing existing levels of poverty. UNESCO points to the need to prepare for massive higher education systems of high quality by:

- restructuring teaching and research in order to meet the needs of the economy, but also to develop ethical values and a spirit of civic participation in democratic processes;

- using public funds efficiently and being held accountable to society through better management, while maintaining the principles of autonomy and academic freedom; - demonstrating the relevance of higher education to society by interacting positively with other levels of the educational system;

In its defense of the long-term role of the state, the World Bank is even more forceful and specific than UNESCO. They concur on the importance of building a policy consensus among the various stakeholders in higher education.

- developing research in higher education as an indispensable factor in economic development, in raising the quality of higher education in general, and in gaining public respect;

- reforming the personnel policies of higher education institutions, with special emphasis on raising the level of competency needed in hiring and promoting teachers;

- evaluating secondary school leavers and reforming secondary schools;

- investing in institutional infrastructure;

- promoting international cooperation in order to support institutions in poor countries, helping to reduce the growing educational and scientific gap between developed and developing nations;

- promoting intercultural understanding through increased exchange of teachers, students, and researchers among different countries; and

- encouraging critically needed, mutual cooperation to help reverse institutional decay in less developed nations, where institutions must learn the value of effectiveness and of developing closer ties with local communities.

Special emphasis is placed by UNESCO on the issues surrounding government funding for higher education, which 
is conceived as a long-term investment for society rather than as a burden on public finances. It points out that while funding sources must be diversified, cost-sharing with students has social and political limits, and it warns against excessive commercialization of higher education. UNESCO stresses that given higher education's status as a public good, no substitute will be found in the future for government funding of higher education, and it disapproves of using a limited concept of rates of return to basic and higher education as a guide for funding policies. Therefore, it calls for increased public and private investment that would allow for a renewal of enrollment growth.

A lesson of experience for UNESCO is the significance of institutional diversity for the health of academic communities, for knowledge development, and the preservation of national and local cultural identity. In its experience, the uncritical adoption of models is harmful for higher education, which must strike a balance between the universality of knowledge and the specificity of local needs.

\section{Conclusion}

Both these approaches call for an important role for government. In its defense of the long-term role of the state, the World Bank is even more forceful and specific than UNESCO. They concur on the importance of building a policy consensus among the various stakeholders in higher education. Both emphasize the need for institutional reform in higher education, and they agree that autonomy and decentralization are key elements in reform. The question now is not so much "reducing the state and expanding the market" as it is a question of building a more capable state. $^{2}$

Another shared issue is change at the institutional level. Decentralization, autonomy, and effective management are stressed as essential ingredients of higher education reform. The need to develop more competent and legitimate public institutions in general has been pointed out as intimately connected with economic reform in less developed countries. $^{3}$

\section{Notes:}

1. Except for countries such as Korea and Taiwan.

2. Merilee Grindle, Challenging the State: Crisis and Innovation in Latin America and Africa, Harvard Institute for International Development, Cambridge, 1993.

3. Naím Moisés, "Latin America: the Morning After," Foreign Affairs (July/August 1995): 45-61.

\section{European Internationalization Programs}

\section{Hans deWit}

Hans deWit is vice president for international affairs, University of Amsterdam, Netherlands, and is past president of the European Association for International Education. P.O.B. 19268, 1000 GG Amsterdam, Netherlands. Fax: 31-20-525-2771

$I^{n}$ n March 1995, the European Parliament approved a new action program in the field of education called SOCRATES. This program incorporates and builds on the well-known program "European Action Scheme for the Mobility of University Students," ERASMUS, that has been in place since 1987 and has made possible an exchange of more than 200,000 students and 15,000 faculty between institutions of higher education in the European Union, including Scandinavia and Austria. The rationale behind ERASMUS at the time of its creation was primarily political and economic - to stimulate a European identity and to develop international competitiveness through education. The creation of the program was a logical addition to the research and development programs launched by the European Commission to keep up with Japan and the United States in the technological race. ERASMUS was followed by similar programs in the area of languages, LINGUA, and in the area of industry-education cooperation, СОМЕTт.

\section{Under ERASMUS, more than 1,500 institu- tions have worked together in more than 2,500 so-called "Interuniversity Cooperation Programs."}

Under ERASMUS, more than 1,500 institutions have worked together in more than 2,500 so-called "Interuniversity Cooperation Programs," or ICPS. Students have come to see ERASMUS as a provider of funding for spending a semester or year at another European institution. A European Credit Transfer System (ECTS) has been developed to integrate the study abroad experience into the home study program. Given the strong emphasis on equal distribution of the program among the member states of the European Union, universities in Southern Europe-historically isolated and not seen as academic equals by their Northern counterparts-have, thanks to ERASMUS, become part of the European academic circle, and have been able to prove that many of the prejudices from the North were lacking a solid basis. 